7. Reprod. Fertil. (1960) 1, 36-44

\title{
PRENATAL MORTALITY IN THE RABBIT ORYCTOLAGUS CUNICULUS*
}

\author{
C. E. ADAMS \\ A.R.C. Unit of Reproductive Physiology and Biochemistry, \\ University of Cambridge \\ (Received I ith fune 1959)
}

\begin{abstract}
Summary. (I) The amount and distribution of prenatal mortality was estimated in three groups of does: Group 1 , a series of 126 first and second pregnancies in seventy-three control does; Group 2, fifteen superovulated and sixteen control does, and Group 3, sixteen does having five ova transferred to one uterine horn and either fifteen or twenty ova transferred to the other uterine horn. (2) Approximately $5 \%$ of the untreated does suffered total loss of their ova before implantation. In does in which implantation occurred, the loss amounted to $9.7 \%$ of the ova before implantation and $18 \%$ of the embryos after implantation. After implantation the loss was distributed as follows: immediately after implantation, $7 \cdot 0 \%$; days 8 to $17,65.8 \%$, and days I 7 to $23,27 \cdot 2 \%$. (3) In superovulated does, having a mean of $28 \cdot 7$ implantations, no reliable estimate can be given for the pre-implantation loss; after implantation $79 \%$ of the embryos were lost compared with $22.6 \%$ in the controls and the mortality tended to occur earlier in the superovulated does. (4) In the Group 3 recipients, there was no significant difference between the two uterine horns in the loss of ova before implantation. After implantation, $23 \%$ of the embryos were lost on the side with few implantations compared with $64 \%$ on the crowded side. (5) It was concluded that 'local' factors (deficiency in placental development or inadequacy of vascular supply) were responsible for the abnormally heavy post-implantation loss in uteri with an excessive number of implantations. (6) It was suggested that there exists a 'ceiling value' for the number of implantation sites that can be maintained successfully.
\end{abstract}

\section{INTRODUCTION}

Surprisingly little information is available concerning the amount and distribution of prenatal mortality in the domestic rabbit. Earlier studies show that approximately $30 \%$ of the ova are lost during pregnancy (Hammond, 1921), but apart from indications of the relative losses occurring before and after

* Read at the Annual Conference, 1959, of the Society for the Study of Fertility. 
implantation, little is known of the way in which the mortality is related to different stages of pregnancy. Extensive studies of prenatal mortality in the wild rabbit revealed not only the heavy wastage in this species (at least $43.3 \%$ of the ova) but also the importance of certain periods when the peak losses occur (Brambell, I948).

Previous estimates of prenatal mortality in the domestic rabbit have been based on counts of the corpora lutea, implantation sites and living foetuses, usually obtained at autopsy late in pregnancy. Such estimates are subject to certain limitations and also incorporate errors inherent in the counts of corpora lutea and implantation sites (Allen, Brambell \& Mills, 1947). A more reliable estimate may be obtained by first making the counts at laparotomy shortly after implantation, followed by a second count either at autopsy near term or at parturition. If this procedure is combined with a measurement of the uterine swellings (at laparotomy) it is also possible to obtain information on the stage of pregnancy when loss occurs (Adams, 1960).

In this paper, a brief account will be given of the results of experiments in which this method was employed to determine the amount and distribution of mortality in three groups of does. Group I : a control series of 126 first and second pregnancies in seventy-three does; Group 2: a series of fifteen does treated with an anterior pituitary preparation, API $18 \mathrm{~B}$, according to the method of Pincus (1940) and Parkes (1943), in order to induce superovulation, and in addition, a control series of sixteen does; and Group 3: a series of sixteen recipient does in which one uterine horn received a small number of transferred ova and the other horn a large number of ova. Two recipients did not become pregnant and are excluded from further discussion.

\section{MATERIALS AND METHODS}

All of the rabbits used were 6 to 8 months old agouti and English crosses, weighing approximately $3.5 \mathrm{~kg}$. For a detailed description of the methods employed in mating, artificial insemination, laparotomy, counting of corpora lutea, measurement of the diameter of uterine swellings and examination of the uterine contents at autopsy, see Adams (1960). Immediately after mating, all does were injected intravenously with 25 i.u. luteinizing hormone (Pregnyl, Organon Laboratories) to ensure against the failure of ovulation. As a rule, the does were examined by laparotomy Io days post coitum, and either parturition was allowed to occur (fifty-five pregnancies in Group I does) or autopsy was performed 28 days post coitum. In the ovum transfer experiment, ova were recovered from the oviducts of superovulated donors $6 \mathrm{o} \mathrm{hr}$ after mating and transferred to the uterus of recipients, which had been given an ovulating injection $72 \mathrm{hr}$ previously. In each recipient, five ova were transferred to one uterine horn (left or right side at random) while either fifteen (four does) or twenty ova (ten does) were transferred to the other uterine horn. 


\section{RESULTS AND DISCUSSION}

GROUP I

\section{Loss of Ova before Implantation}

During the period which precedes implantation, a doe may experience total, partial, or no loss of ova. The relative importance of these three categories is illustrated in Text-fig. I, based on 126 pregnancies. Table 1 summarizes the
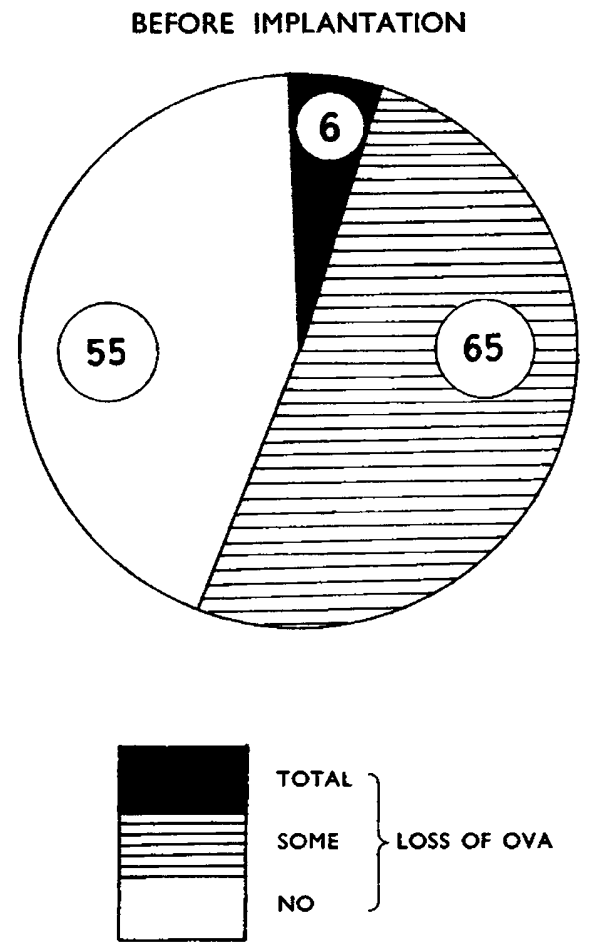

TExT-FIG. I. Diagrammatic representation of the distribution of 126 pregnancies (Group 1 ) according to the loss of some, all, or none of the ova before implantation. (Number of pregnancies shown in the small circles.)

Table I

SUMMARY OF LOSSES OCCURRING BEFORE AND AFTER IMPLANTATION IN GROUP I DOES

\begin{tabular}{|c|c|c|c|}
\hline & Total loss & Remainder & Total \\
\hline Pre-implantation loss $\left\{\begin{array}{l}\text { No. of pregnancies } \\
\text { No. of corpora lutea } \\
\text { No. of eggs failed to implant }\end{array}\right.$ & $\begin{array}{r}6 \\
109 \\
109\end{array}$ & $\begin{array}{r}120 \\
1347 \\
132^{*}\end{array}$ & $\begin{array}{r}126 \\
1456 \\
241\end{array}$ \\
\hline Post-implantation loss $\left\{\begin{array}{l}\text { No. of pregnancies } \\
\text { No. of implants } \\
\text { No. of implants failed to survive }\end{array}\right.$ & $\begin{array}{r}4 \\
33 \\
33\end{array}$ & $\begin{array}{r}116 \\
1182 \\
213\end{array}$ & $\begin{array}{r}120 \\
1215 \\
246\end{array}$ \\
\hline No. of live embryos at 28 days & - & 969 & 969 \\
\hline
\end{tabular}

* $\mathrm{I} 54$ if polyovuly is taken into account. 
losses occurring before and after implantation. Although only six does (4.7\%) suffered total loss of ova, their contribution to the general total of ova lost was disproportionately large $(45.2 \%)$ and for this reason this small group is considered separately. In the I 20 remaining pregnancies in which either some or all of the ova survived up to the time of implantation, 132 of the ova $(9.7 \%)$ were lost before implantation. If a correction is applied for polyovuly these figures become $\mathrm{I} 54$ and II.2\% respectively. This level of pre-implantation mortality, which is very similar to that observed by Brambell \& Mills (1947) in the wild

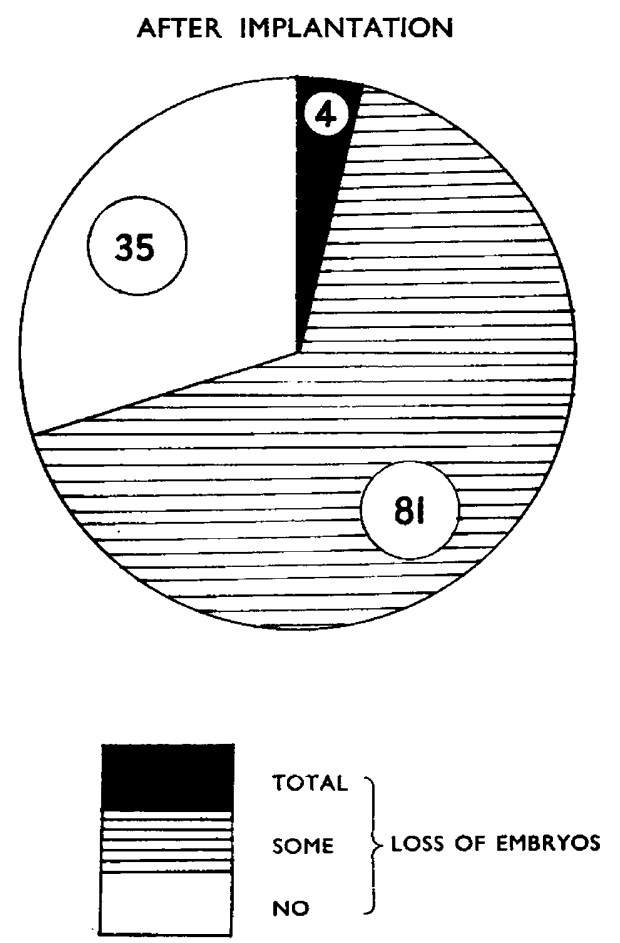

TEXT-FIG. 2. Diagrammatic representation of 120 pregnancies (Group I) according to the loss of some, all, or none of the embryos after implantation. (Number of pregnancies shown in the small circles.)

rabbit ( $10 \cdot 2$ to $13 \cdot 0 \%$ ), is regarded as a high one. The distribution of the loss during the pre-implantation period was not analysed in the present study, but in an earlier study (Adams, 1956) it was found that only $4.5 \%$ of the ova failed to become fertilized. It therefore seems likely that more than half of the pre-implantation loss is associated with blastocyst stages, since only a minor percentage of fertilized ova fail to develop into blastocysts (unpublished observations).

\section{Loss of Embryos after Implantation}

The distribution of the I 20 pregnancies for total, partial, or no loss of embryos after implantation is shown in Text-fig. 2. Total loss may occur by resorption B* 
(before day 19) or abortion (after day 19), whilst partial loss generally occurs through resorption, or in late foetal stages through death without resorption. Only a minor percentage $(3.3 \%)$ of the pregnancies ended prematurely, in each case by resorption, but a much higher proportion $(70 \cdot 8 \%)$ involved partial loss of the litter. Altogether 246 embryos $(20 \cdot 2 \%$ of the implantation sites or $18 \%$ of the ovulations) were lost before term.

It has been found that a satisfactory analysis of the distribution of mortality after implantation could be based on examination of the uterus at autopsy on day 28 (see Table 2) when taken in conjunction with the measurements of the uterine swellings at $\mathrm{I} 0$ and $\mathrm{I} 7$ days after mating (Adams, I960). It was concluded that implantation sites which disappear before day $28(\mathrm{I} \cdot 2 \%$ of the total $)$ represent mortality occurring immediately after implantation, the presence of atrophic placentae represents loss occurring from soon after implantation to

TABLE 2

Distribution OF PRENATAL MORTALITY BETWEEN IMPLANTATION AND DAY 28 post coitum

\begin{tabular}{|c|c|c|c|c|c|c|c|c|c|c|}
\hline & \multirow{2}{*}{$\begin{array}{l}\text { No. of } \\
\text { does }\end{array}$} & \multirow{2}{*}{$\begin{array}{c}\text { No. of } \\
\text { implant. } \\
\text { sites }\end{array}$} & \multicolumn{2}{|c|}{ Disappeared } & \multicolumn{2}{|c|}{$\begin{array}{l}\text { Atrophic } \\
\text { placenta }\end{array}$} & \multicolumn{2}{|c|}{ Dead foetus } & \multicolumn{2}{|c|}{ Live foetus } \\
\hline & & & No. & $\%$ & No & $\%$ & No. & $\%$ & No. & $\%$ \\
\hline 1. Untreated & 60 & 644 & 8 & $7 \cdot 0$ & 75 & 65.8 & $3^{I}$ & $27 \cdot 2$ & $53^{\circ}$ & $82 \cdot 3$ \\
\hline 2. $\left\{\begin{array}{l}\text { Untreated } \\
\text { Superovulated }\end{array}\right.$ & $\begin{array}{r}16 \\
8\end{array}$ & $\begin{array}{l}156 \\
247\end{array}$ & $\begin{array}{r}3 \\
43\end{array}$ & $\begin{array}{r}8 \cdot 3 \\
22 \cdot 0\end{array}$ & $\begin{array}{r}28 \\
145\end{array}$ & $\begin{array}{l}77 \cdot 8 \\
74 \cdot 4\end{array}$ & $\begin{array}{l}5 \\
7\end{array}$ & $\begin{array}{r}13 \cdot 9 \\
3 \cdot 6\end{array}$ & $\begin{array}{r}120 \\
52\end{array}$ & $\begin{array}{l}76 \cdot 9 \\
21 \cdot 0\end{array}$ \\
\hline 3. $\left\{\begin{array}{l}\text { One uterine horn } \\
\text { receiving } 5 \text { ova } \\
\text { Other uterine } \\
\text { horn receiving i } 5 \\
\text { or } 20 \text { ova }\end{array}\right.$ & & 201 & 23 & $\begin{array}{l}14 \cdot 3 \\
17 \cdot 8\end{array}$ & $\begin{array}{l}10 \\
86\end{array}$ & $\begin{array}{l}71 \cdot 4 \\
66 \cdot 7\end{array}$ & 20 & $\begin{array}{r}14 \% 3 \\
15.5\end{array}$ & $\begin{array}{l}47 \\
72\end{array}$ & $\begin{array}{l}77^{\circ} 0 \\
35^{\circ}\end{array}$ \\
\hline
\end{tabular}

Data based on 98 pregnancies and 1309 implantation sites.

approximately day I 7 , whilst the presence of dead foetuses represents mortality occurring later than day i 7 post coitum. As none of the dead foetuses weighed more than $\mathrm{Io} \mathrm{g}$, it was further concluded that foetal mortality did not occur later than day 23 post coitum. It was estimated that $7 \%$ of the embryos died shortly after implantation, $66 \%$ died between days 8 and $\mathrm{I} 7$, and $27 \%$ were lost between days I7 and 23. Thus, as in the wild rabbit (Brambell \& Mills, I948), the peak period of mortality falls between implantation and midpregnancy, but there is also a secondary peak occurring about days 17 to 23 .

In attempting to offer an explanation for this mortality, it is interesting to relate it to certain processes which accompany the various stages of pregnancy. The early embryo relies upon the yolk sac (bilaminar omphalopleur) for its nutrition, but this structure begins to degenerate about the Ioth day of pregnancy, when it is superseded by the chorio-allantoic placenta. Although the formation of the chorio-allantoic placenta is initiated at the time of implantation its characteristics are not fully developed until about the 12th day of pregnancy (Amoroso, 1952). It may be assumed that this transition engenders a critical period for the embryo. Later in this paper, an experiment will be 
described which illustrates the importance of the local environment for the survival of the rabbit embryo. The secondary peak of mortality between days I 7 and 23 post coitum could well result from mechanical disturbances, as it coincides with the final phase of uterine enlargement when the tension on the spheroidal conceptus is at a maximum. About day 20, the spheroidal conceptus assumes a cylindroid appearance and the embryo rotates through $90^{\circ}$ to bring its long axis into a position which is parallel to that of the uterus (Reynolds, 1946).

GROUP 2

\section{Loss of Ova before Implantation}

In the group of fifteen superovulated does, the mean number of implantations as determined at laparotomy Io days post coitum, was 28.7 compared with 9.7 in the sixteen untreated does (Table 3 ). The maximum number of implantations

TABLE 3

THE NUMBER OF CORPORA LUTEA AND IMPLANTATION SITES (COUNTED IO
DAYS AFTER MATING) AND LIVE FOETUSES AT 28 DAYS IN CONTROL AND
SUPEROVULATED DOES OF GROUP 2

Means \pm S.E. Ranges in parentheses.

* Based on eight does.

recorded in one uterine horn was $2 \mathrm{I}$. The mean number of corpora lutea (also counted ro days post coitum) in the treated does was $57^{\circ} 6$, but it is suspected that this figure is unreliable as some of the corpora lutea may have been derived from follicles that luteinized without ovulation. Consequently, no reliable estimate can be given either for the number of ovulations or for the proportion of ova lost before implantation. For the same reason, Parkes (1943) also refrained from estimating the proportion of ova lost in superovulated does. However, some information on the number of ovulations in superovulated does can be derived from a related study involving sixty-seven similar does in which the mean number of ovulation points was $3^{\mathrm{I}} \cdot 9$ when examined $6 \mathrm{o} \mathrm{hr}$ post coitum. It would therefore appear that the pre-implantation loss in the superovulated does was of approximately the same order as in the controls.

\section{Loss of Embryos after Implantation}

Seven of the superovulated does are not available for the estimate of loss occurring after implantation, as they were used for experiments on surgically induced mortality. In the remaining eight does, the mean number of living young at 28 days was $6 \cdot 5$, compared with $7 \cdot 5$ in the sixteen untreated does. This 
means that the untreated does lost $22.6 \%$ of their embryos whereas in the treated does $79.0 \%$ of the embryos were lost.

The distribution of the loss in Group 2 is shown in Table 2. In view of the very different levels of mortality in the superovulated and control series, the pattern of loss is remarkably similar, except for a tendency for it to occur slightly earlier in the treated does. This is brought out by comparing the two series for the number of uterine swellings measuring less than $12 \mathrm{~mm}$ on day Io (I $2 \mathrm{~mm}$ is the minimal size compatible with further development [Adams, I960]), namely $3.7 \%$ in the controls and $42 \%$ in the treated does.

These results support the earlier conclusion of Parkes (1943) that 'the reasons why the uterus is unable to support the growth of supernormal numbers of embryos is not clear, but in view of the stage of pregnancy at which regression seems to have taken place, it is unlikely to be primarily of mechanical or metabolic origin'. The same author suggested that further work was necessary

TABLE 4

THE INFLUENCE OF NUMBER OF EGGS TRANSFERRED TO RECIPIENT DOES (GROUP 3) ON PRENATAL MORTALITY IN THE RABBIT

\begin{tabular}{|c|c|c|}
\hline & $\begin{array}{l}\text { One uterine } \\
\text { horn }\end{array}$ & $\begin{array}{c}\text { Other uterine } \\
\text { horn }\end{array}$ \\
\hline Mean No. of eggs transferred & $5^{\circ} 0 \pm 0^{\circ} 0$ & $\begin{array}{l}\text { I8.57 } \pm 0.66 \\
(\text { I } 5 \text { to } 20)\end{array}$ \\
\hline Mean No. of implantations & $\begin{array}{c}4 \cdot 36 \pm 0.22 \\
(3 \text { to } 5)\end{array}$ & $\begin{array}{l}\text { 1 } 4.36 \pm 0.45 \\
\text { (12 to I } 7 \text { ) }\end{array}$ \\
\hline $\begin{aligned} & \text { Mean No. of sites }>12 \mathrm{~mm} \text { at } \\
& \text { ro days }\end{aligned}$ & $\begin{array}{l}4 \cdot 00 \pm 0 \cdot 2 \text { I } \\
(3 \text { to } 5)\end{array}$ & $\begin{array}{l}\text { I0.50 } 50.88 \\
(5 \text { to } 16)\end{array}$ \\
\hline $\begin{array}{l}\text { Mean No. of live foetuses at } \\
28 \text { days }\end{array}$ & $\begin{array}{l}3 \cdot 36 \pm 0.33 \\
(1 \text { to } 5)\end{array}$ & $\begin{array}{l}5.14 \pm 0.72 \\
(1 \text { to } 11)\end{array}$ \\
\hline
\end{tabular}

Data based on fourteen does. Means \pm S.E. Ranges in parentheses.

to determine whether the failure was caused by a deficiency of progesterone. Recently, egg transfer experiments, described below, have provided an answer to this question.

\section{GROUP 3}

Since transuterine migration of ova does not occur in the rabbit (Boyd, Hamilton \& Hammond, I944; Brambell, I948), it is possible by means of egg transfer to create in one uterine horn a state of 'overcrowding', resembling the condition normally prevailing in a superovulated doe, and use, at the same time, the other uterine horn as a 'control' within the same animal. In this manner, it is possible to create artificially a situation in which the rabbit carries two sets of embryos, of which only one is subject to overcrowding and yet both sets are subject to the influence of the same 'hormonal milieu'.

\section{Loss of Ova before Implantation}

Details of the number of ova transferred and the number of implantation sites are given in Table 4 . In the fourteen horns which received five ova each, $87 \%$ of the ova survived to implantation while in the fourteen horns which received 
fifteen or twenty ova each the survival rate was $78 \%$ : the difference in survival rates is not statistically significant.

\section{Loss of Embryos after Implantation}

After implantation, the difference in mortality between the embryos present in the two uterine horns was very large. Whereas not more than $23 \%$ of the embryos (fourteen out of sixty-one) died on the control side, $64 \%$ (129 out of 20I) died in the crowded uterine horns. The distribution of the mortality occurring after implantation is shown in Table 2. It is apparent that in spite of the greatly increased mortality on the crowded side, the distribution of the mortality with stage of pregnancy resembles very closely that in the control series. However, reference to the number of embryos measuring less than $12 \mathrm{~mm}$ at io days (Table 3 ), namely $8.2 \%$ and $26.8 \%$, shows that the loss tends to occur earlier in the crowded uterine horns than in the control series.

The results of this experiment indicate that the mortality associated with the implantation of abnormally large numbers of embryos is not dependent upon a hormonal deficiency, e.g. that of progesterone, for if this were the case, the mortality would be expected to occur equally in both uterine horns. Some other factor, probably of a 'local' character, must be responsible for the mortality in the crowded uterine horn. One possible explanation could be that when the number of implanting ova becomes excessive, placental development is adversely affected to such an extent that the embryos cannot survive. It is also possible that the normal vascular supply to the uterus is insufficient to support the development of an abnormally large number of placentae and embryos.

It appears that there is an upper limit to the number of implantation sites that can be successfully maintained and beyond a certain level the mortality tends to fall on the 'litter' as a unit rather than on individual embryos, which by competition inter se prejudice each other's survival. On this basis, we should expect breed, strain and even individual variations to exist in the ceiling value for implantation sites. In this connection, it is interesting that attempts to increase the litter size of small-breed does by increasing the number of eggs transferred were unsuccessful and, in fact, produced the opposite effect (Venge, 1950). It follows that when different breeds are being used as recipients care should be taken to ensure that the number of ova transferred is optimal in each case. If too few ova are transferred the litter size will be directly limited whilst if too many are transferred the limitation will operate indirectly through the 'overcrowding effect' associated with excessive numbers of implantations.

\section{ACKNOWLEDGMENTS}

I am indebted to Dr T. Mann, F.R.s., for reading and discussing the manuscript. The preparation, APı 18 B, was kindly made available by Dr A. S. Parkes, F.R.s.

\section{REFERENCES}

Adams, C. E. (1956) A study of fertilization in the rabbit: the effect of post-coital ligation of the fallopian tube or uterine horn. F. Endocrin. 13, 296.

Adams, C. E. (1960) Studies on prenatal mortality in the rabbit, Oryctolagus cuniculus: the amount and distribution of the loss before and after implantation. $\mathcal{F}$. Endocrin. 19, 325. 
Allen, P., Brambell, F. W. R. \& Mills, I. H. (ig47) Studies on sterility and prenatal mortality in wild rabbits. The reliability of estimates of the prenatal mortality based on counts of corpora lutea, implantation sites and embryos. 7. exp. Biol. 23, 3 I 2.

Amoroso, E. C. (1952) 'Placentation'. Marshall's Physiology of Reproduction, vol. 2, ed. A. S. Parkes. Longmans, Green \& Co, London.

Boyd, J. D., Hamilton, W. J. \& Hammond, J., JR. (r944) Transuterine (internal) migration of the ovum in sheep and other mammals. 7. Anat., Lond. $\mathbf{7 8}, 5$.

Brambell, F. W. R. (1948) Prenatal mortality in mammals. Biol. Rev. 23, 370.

Brambell, F. W. R. \& Mills, I. H. (1947) Studies on sterility and prenatal mortality in wild rabbits. Part 3. The loss of ova before implantation. 7. exp. Biol. 24, 192.

Brambell, F. W. R. \& Mills, I. H. (1948) Studies on sterility and prenatal mortality in wild rabbits. Part 4. The loss of embryos after implantation. 7. exp. Biol. 25, 241 .

Hammond, J. (192I) Further observations on the factors controlling fertility and foetal atrophy. $\mathcal{J}$. agric. Sci. I1, 337.

Parkes, A. S. (1943) Induction of superovulation and superfecundation in rabbits. 7. Endocrin. 3, 268.

Pincus, G. (1940) Superovulation in rabbits. Anat. Rec. 77, 1.

Reynolos, S. R. M. ( I946) The relation of hydrostatic conditions in the uterus to the size and shape of the conceptus during pregnancy. A concept of uterine accommodation. Anat. Rec. 95, 283.

VENGe, O. (1950) Studies of the maternal influence on the birth weight in rabbits. Acta zool., Stockh. 3I, 1 . 